\title{
An unusual presentation of huge paraovarian cyst as papillary serous cyst adenofibroma: a rare case report
}

\author{
Namita Agrawal $^{1 *}$, Nishi Gupta ${ }^{1}$, Sukriti Chandra ${ }^{1}$, Shubha Gupta $^{2}$, S. Fayyaz $^{1}$
}

\begin{abstract}
${ }^{1}$ Department of Obstetrics and Gynecology, ${ }^{2}$ Department of Histopathology, Santokba Durlabhji Memorial Hospital and Research Centre (SDMH), Jaipur, Rajasthan, India
\end{abstract}

Received: 25 June 2018

Accepted: 26 July 2018

\section{*Correspondence:}

Dr. Namita Agrawal,

E-mail: namitaagarwalsms@gmail.com

Copyright: () the author(s), publisher and licensee Medip Academy. This is an open-access article distributed under the terms of the Creative Commons Attribution Non-Commercial License, which permits unrestricted non-commercial use, distribution, and reproduction in any medium, provided the original work is properly cited.

\begin{abstract}
Paraovarian cysts constitute $10-20 \%$ of all adnexal masses and are usually less than two centimeter in diameter. Authors reported a 20-year-old unmarried female with vague abdominal discomfort since 1 year. On examination abdomen was uniformly distended with central position of umbilicus. Ultrasonography showed a large cystic mass extending from pelvis to pancreas likely of ovarian origin. Biochemical evaluation was not suggestive of malignant nature of this cystic mass. So, with due care of cosmesis, surgery was planned. After the midline vertical incision, peritoneal washings were collected for oicytological analysis to further exclude malignancy. Then $5 \mathrm{~mm}$ cannula with trocar was inserted into the cyst to suck out the fluid then shrunken cystic wall was exteriorised. Right ovary was absolutely healthy. Enucleation of the cyst was done with preservation of ovary. Histopathology reported as a papillary serous cyst adenofibroma. Follow up period was uneventful.
\end{abstract}

Keywords: Paraovarian cysts, Papillary serous cyst adenofibroma

\section{INTRODUCTION}

Paraovarian cyst usually arises from the mesothelial covering of the peritoneum or remnants of paramesonephric and mesonephric origin, so histologically they are covered by a single layer of ciliated columnar or flattened cells. ${ }^{1}$ Paraovarian cysts constitute $10-20 \%$ of all adnexal masses. ${ }^{2}$ The cases have been reported in all female age groups and seemed to be most common in the third to fifth decades of life. The origin of these pelvic masses may be non-neoplastic, simple cystic or neoplastic. ${ }^{3}$ They are usually benign and hardly $2 \mathrm{~cm}$ in maximum diameter. ${ }^{2}$ They are usually asymptomatic and incidental finding on laparotomy or laparoscopy. If symptomatic, symptoms are usually due to pressure on to the surrounding organ e.g. Bowel and bladder or due to complications such as enlargement, perforation, haemorrhage, infection. ${ }^{4}$ Definitive management of simple paraovarian cyst is enucleation of cyst with preservation of both ovary and fallopian tube. In case of complicated cyst excision of ovary and/or fallopian tube may be required. .7 $^{5-7}$

Authors are presenting a case report of huge paraovarian cyst in a 20 years old unmarried female managed by enucleation of cyst with preservation of ovary for future fertility and normal hormonal milieu.

\section{CASE REPORT}

A 20-year-old unmarried female presented at authors' outpatient department on $13^{\text {th }}$ February 2018 with complaints of vague abdominal discomfort since 1 year. Patient attained menarche at 13 years of her age with 
regular cycles of 28 days with normal flow for 3-4 days associated with mild dysmenorrhoea. This abdominal discomfort was not aggravated with meal, exertion or any kind of body posture. There was no history of colicky abdominal pain, nausea, vomiting diarrhoea or constipation. On examination she is well built with height and weight $154 \mathrm{~cm}$ and $74 \mathrm{Kg}$ respectively making her BMI $31.20 \mathrm{~kg} / \mathrm{m}^{2}$. Her vitals were within - normal -limit. On abdominal examination abdomen was uniformly distended with central position of umbilicus, no hernial site bulging, afebrile to touch, non-tender and non-tense. Abdominal girth at the level of umbilicus was $40 \mathrm{~cm}$ with no fluid thrill and bowel sounds heard over flank. The grey scale ultrasonography was advised for this which was suggestive of large cystic mass extending from pelvis to pancreas likely of ovarian origin. Contrast-enhanced computed tomography (CECT) abdomino-pelvis was performed to find out the exact origin and clear planes of the lesion. That revealed a large well-defined cystic lesion $(\sim 29.8 \times 24.5 \times 14.4 \mathrm{~cm})$ in the abdomino-pelvic region, extending superiorly in retroperitonium up to the level of pancreas and inferiorly the pelvis likely ovarian origin? benign epithelial neoplasm (Figure 1).
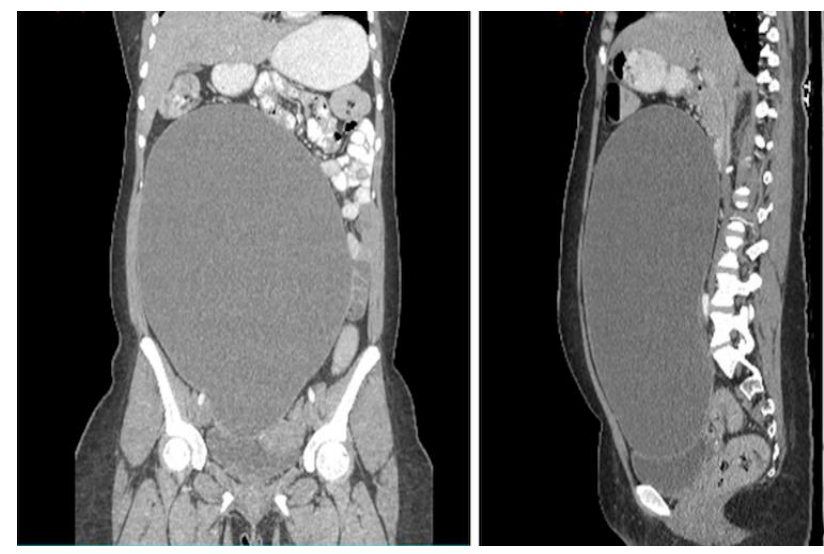

Figure 1: Coronal and saggital images reveal a large cystic mass extending from pelvis to midabdominal region.

For confirmation tumor markers were advised which were CA-125, CEA, $\beta$-HCG, LDH and Prolactin were $5.5,2.03,<2.39,260$ and 12.4 respectively. All of this above-mentioned work up was not suggestive of malignant nature of this cystic mass. So, with due care of cosmesis for young unmarried girl midline vertical incision below the umbilicus of approximately $4 \mathrm{~cm}$ was made peritoneal washings collected with $50 \mathrm{cc}$ normal saline for cytological analysis to further exclude malignancy. Then $5 \mathrm{~mm}$ cannula with trocar was inserted into the cyst in view to suck out whole of the fluid without spillage, 7 litres of fluid was drained out then shrunken cyst wall was exteriorized which was showing outstretched approximately $25 \mathrm{~cm}$ right sided fallopian tube arising from right sided broad ligament. Right ovary was absolutely healthy. Enucleation of the cyst was done with preservation of ovary. Histopathology shows outer surface of the cystic flap is congested and capsulated while irregular inner wall shows multiple papillary excrescences at few places and finally reported as a papillary serous cyst adenofibroma (Figure 2). Follow up period was uneventful.

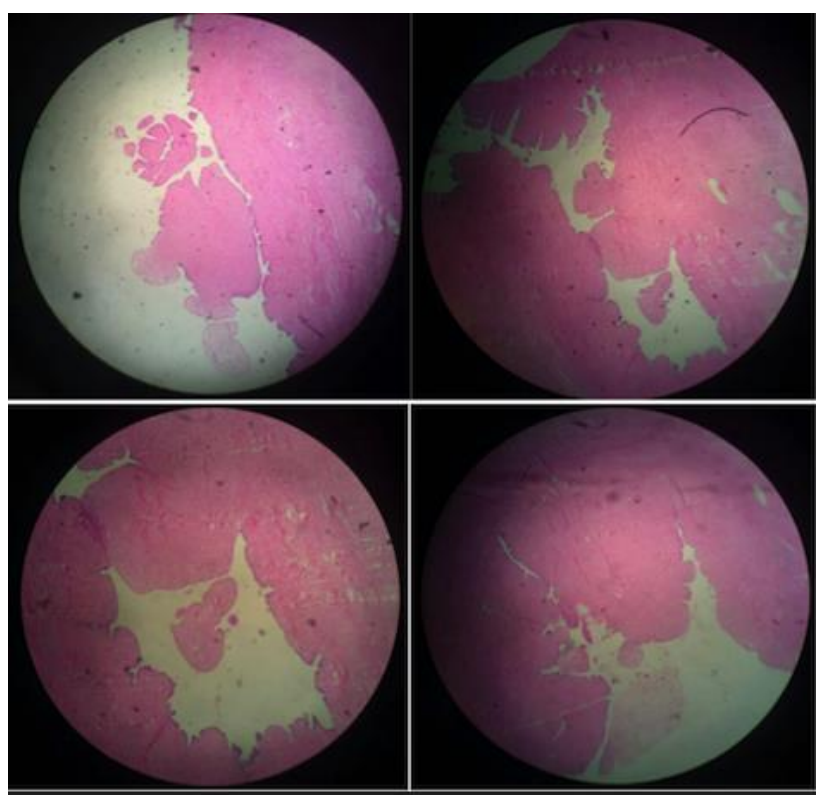

Figure 2: Histopathological examination revealed papillary serous cyst adenofibroma.

\section{DISCUSSION}

Paraovarian cysts are commonly seen in third and fourth decade of life. Usually are asymptomatic and smaller in size. When they are larger in size they become symptomatic due to mass effects. Studied patient presented with abdominal bulge causing her abdominal discomfort. There is no strict numerical definition and uniformly accepted criteria for huge paraovarian cyst. Though any mass which is so large and cystic in consistency rarely be malignant yet careful diagnostic workup including tumor markers and imaging should be carried out to exclude malignancy.

Huge paraovarian cyst always require surgical excision due to mass effect and prevention of further development of complications. Enucleation of paraovarian cyst with ovarian salvage is the standard treatment. ${ }^{6,7}$ In present case as this nonpedunculated paraovarian cyst was about $30 \times 25 \mathrm{~cm}$ in size in close proximity with right fallopian tube arising in broad ligament cyst was excised with right fallopian removal and right ovary was preserved. Now-adays laparoscopy is being widely used in gynae cases as minimally invasive surgery. It has reduced postoperative morbidity, pain, and pulmonary complications, shortened hospital stays, moved many procedures into the outpatient arena, and perhaps reduced overall costs. ${ }^{8}$ In present case due to risk of cyst rupture and limited working space laparoscopy was not found to be feasible, so open surgical intervention was performed. Open surgery remains the gold standard route to deal with giant 
paraovarian cysts. Aspiration of the cyst using a closed system followed by excision is a safe and effective treatment. ${ }^{9}$

In various histomorphologies of paraovarian cysts are papillary serous cyst adenoma, borderline tumor, and endometrial sarcoma arising from paraovarian cyst. ${ }^{1,10}$ In our patient histopathology revealed papillary serous cyst adenofibroma with no solid component.

It is very difficult to diagnose paraovarian cyst preoperatively, but it should be included in differential diagnosis of abdominopelvic masses. Preservation of ovary in surgical intervention increases the future reproductive potential and hormonal status of a lady.

Funding: No funding sources

Conflict of interest: None declared

Ethical approval: Not required

\section{REFERENCES}

1. Gupta A, Gupta P, Manaktala U, Khurana N. Clinical, radiological, and histopathological analysis of paraovarian cysts. J Mid-life Health. 2016;7(2):78-82.

2. Bohîlțea RE, Cîrstoiu MM, Turcan N, Ionescu CA. Ultrasound diagnostic of mesonephric paraovarian cyst-case report. J Med Life. 2016;9(3):280-3.

3. Smorgick N, Herman A, Schneider D, Halperin R, Pansky M. Paraovarian cysts of neoplastic origin are underreported. JSLS: J Society Laparoendoscop Surg. 2009;13(1):22-6.

4. Hernon M, McKenna J, Busby G, Sanders C, Garden A. The histology and management of ovarian cysts found in children and adolescents presenting to a children's hospital from 1991 to 2007: a call for more paediatric gynaecologists. BJOG: Int J Obstet Gynaecol. 2010;117(2):181-4.

5. Seckin B, Ozdener T, Tapisiz OL, Batioğlu S. Laparoscopic treatment of ovarian cysts in adolescents and young adults. J Pediat Adolescent Gynecol. 2011;24(5):300-3.

6. Agarwal P, Agarwal P, Bagdi R, Balagopal S, Ramasundaram M, Paramaswamy B. Ovarian preservation in children for adenexal pathology, current trends in laparoscopic management and our experience. J Indian Assoc Pediatr Surg. 2014;19(2):65.

7. Darwish AM, Amin AF, Mohammad SA. Laparoscopic management of paratubal and paraovarian cysts. JSLS: J Society Laparoendoscop Surg. 2003;7(2):101-6.

8. Col RS, Col AS, Col NG, Col DB, Col AS. Major laparoscopic surgery under regional anesthesia: A prospective feasibility study. Med J Armed Forces India. 2015;71(2):126-31.

9. Banta HD. Minimally invasive surgery. Implications for hospitals, health workers, and patients. Br Med j. 1993;307(6918):1546-9.

10. Lee CI, Chiang KJ, Yu MH, Su HY, Chao TK, Wang YC. Rare case of a paratubal cystadenoma with bilateral hydrosalpinges in an infertile woman. Taiwanese J Obstet Gynecol. 2014;53(2):239-40.

Cite this article as: Agrawal N, Gupta N, Chandra S Gupta S, Fayyaz S. An unusual presentation of huge paraovarian cyst as papillary serous cyst adenofibroma: a rare case report. Int J Reprod Contracept Obstet Gynecol 2018;7:3887-9. 